\title{
BEVILAQUA, C. B.; VANDER VELDEN, F. (orgs.). 2016. Parentes, vitimas, sujeitos: perspectivas antropológicas sobre relações entre humanos e animais. Curitiba/ São Carlos: Editora da UFPR/Edufscar. 446 pp.
}

\author{
MESSIAS BASQUES
}

A coletânea organizada por Ciméa Beviláqua e Felipe Vander Velden resulta de uma iniciativa pioneira na antropologia brasileira. Os capítulos que compõem o livro foram originalmente apresentados no grupo de trabalho Animais e humanos em contextos urbanos e rurais: novas perspectivas sobre relações interespecificas, na 28 ${ }^{a}$ Reunião Brasileira de Antropologia, realizada em São Paulo no ano de 2012. Se o estudo das relações entre humanos e animais constitui uma "preocupação clássica da pesquisa antropológica" (:11), a iniciativa de Bevilaqua e Vander Velden ocupa um lugar de destaque na história dos estudos da questão animal no Brasil, por se tratar do primeiro grupo de trabalho dedicado exclusivamente ao tema em um evento acadêmico nacional. Nos últimos anos, o número de livros, edições especiais de revistas de antropologia, seminários e pesquisas de mestrado e doutorado dedicadas à temática cresceu de maneira constante, dando lugar a "campos subdisciplinares" como a antrozoologiae a etnoprimatologia.

$\mathrm{Na}$ Introdução, Bevilaqua e Vander Velden destacam que "as complexidades etnográficas e teóricas de formas de conceptualização, coexistência e engajamento entre animais e seres humanos em contextos urbanos e rurais não indígenas" (:12) passaram a atrair a atenção de um número significativo de pesquisadores. A diversidade de temas e contextos etnográficos presentes no livro revela uma convergência em torno de um desafio comum: tratar a fronteira entre humanos e não-humanos como "um problema etnográfico, cuja resposta depende necessariamente dos atores e de suas circunstâncias"(:12-13).

Na primeira parte, Domesticidades, parentescos, genealogias, os capítulos apresentam modulações específicas da utilização do vocabulário do parentesco nas formas de convivência e nas relações humano-animal. A partir de uma pesquisa junto a uma comunidade de resgate e adoção de gatos no Rio de Janeiro, Andréa Osório propõe uma discussão sobre relações de parentesco. Segundo a autora, a atribuição de uma imagem de "infância perpétua" é parte de um processo de "desanimalização" que nunca se completa. O afeto pelos animais de "estimação" repercute em concepções de parentesco e de amor familiar, configurando uma obrigação moral e social. A seu ver, "na qualidade de sujeitos de afeto, animais de estimação são "crianças da casa" e os seus "pais" tornam-se responsáveis pelos animais aban- 
donados nas ruas (:73). Na condição de vítimas, os animais são concebidos como sujeitos e não como objetos, embora tenham donos que os veem, simultaneamente, como propriedades, filhos e animais de estimação.

O trabalho de Natacha Simei Leal é um contraponto às políticas de contenção da reprodução de animais domésticos, pois aborda justamente a celebração da fertilidade no universo da pecuária de elite. A partir da descrição de uma festa de quinze anos dedicada ao célebre touro nelore Ranchi, progenitor do impressionante número de 150 mil descendentes, somos apresentados ao triplo dispositivo que engendra a excelência dos animais: o pedigree, a superalimentação e a participação bem-sucedida nas pistas de julgamento realizadas em feiras e exposições. Se a pecuária de elite parece conter um aspecto "antieconômico" (:17), uma vez que o comércio de sêmen pode operar com valores desproporcionais ao incremento industrial e comercial da carne, por outro lado, como nos lembram Gabriel Tarde e o recente prêmio Nobel Richard Thaler: a racionalidade econômica anda de mãos dadas com as paixões humanas. Natacha Leal demonstra que "os bovinos de elite são mais que símbolo", pois "o investimento de um criador em uma rês é parte tanto da trajetória dele próprio, como da do animal", mediante uma "troca intermitente de reputações entre reses e homens que fundamenta a pecuária de gado de elite" (:98).

Ivana Teixeira também aborda o pedigree e o julgamento dos padrões fenotípicos e de temperamento das raças em sua etnografia de concursos de beleza canina. A premiação dos cães nesses concursos e os títulos por elesobtidos passam a figurar em sua reputação, como modelos exemplares de suas raças. Porém, “as qualidades do cão podem ser hipertrofiadas ou prejudicadas por seu acompanhante humano" (:16), chamado de handler, que pode ser acusado de trapaça ou ser alvo de críticas dirigidas à sua eventual interferência. Nesse sentido, os concursos são descritos pela autora como"uma espécie de ritual de manutenção da noção de raça, que é sustentada pelo pedigree, em que pese o fato de que o cão deva ser de raça e não, necessariamente, de uma determinada raça" (:116).

$\mathrm{Na}$ segunda parte, Produzir a vida e administrar a morte, os capítulos tratam das relações humano-animal em face da tríade criação-cuidado-consumo, refletindo sobre os diferentes agenciamentos entre humanos e animais. Caetano Sordi analisa a adoção das técnicas de "manejo racional" entre produtores de carne e as suas implicações para o problema do sofrimento animal. A suposta racionalização do manejo não deixa de expressar a ambiguidade entre a subjetivação e a objetivação dos animais, onde "o animal dotado de agência dá lugar à figura da carcaça como matéria-prima da indústria de carne" (:17). Para Sordi, o manejo racional pode ser interpretado como "o capítulo mais recente das tecnologias de administração da subjetividade animal nos contextos críticos de predação social dos animais" (:136). A transformação de uma noção de vida plena em uma vida objetificada seria, portanto, a expressão de uma "biopolítica" que engloba e reduz homens e animais a "viventes sencientes" (:139).

Apesar de ser um terreno praticamente inexplorado na antropologia brasileira, o número de pesquisas sobre a temática da caça tem crescido nos últimos anos. O capítulo de Fernandez et al. se insere nesse contexto e descreve as atividades de caça em uma floresta urbana no Rio de Janeiro, onde os limites jurídicos da legislação ambiental se chocam com a presença histórica de "um campesinato integrado ao meio urbano" (:160), exigindo a adaptação das técnicas de caça para que os seus prati- 
cantes não sejam denunciados pelos estampidos das armas de fogo. No caso analisado pelos autores, a caça se tornou uma forma de subsistência alimentar subsidiária, mas constitutiva da "paisagem cultural do Maciço da Pedra Branca” (:160). Trata-se de uma prerrogativa masculina associada à celebração de festas, onde a carne é servida após a degustação de bolos.

É curioso notar que a carne seja servida após o que chamamos de "sobremesa”, já que os doces são geralmente consumidos em nossas refeições na sequência de alimentos salgados. O capítulo de Maria Isabel Dantas trata de outro tipo de "doce" ou sobremesa, encontrado no sertão do Rio Grande do Norte, cuja matéria-prima é o sangue de porcos. A criação desses animais é uma prerrogativa feminina associada ao ambiente familiar e doméstico. A discussão se concentra em um aparente dilema: como abater e consumir animais que convivem em uma "família ampliada"? A solução passa, entre outros aspectos, pela intervenção de um profissional especializado no abate, chamado marchante. Nas palavras da autora, para que se possa consumi-los "faz-se necessário que os vestígios de humanidade e de animalidade que lhes são atribuídos sejam depurados no momento do abate e durante o cozimento de sua carne ou de seu sangue" (:178). Portanto, "primeiro desumaniza-se e, em seguida, desanimaliza-se" (ibid.). Há uma interessante releitura das noções de proximidade e distanciamento, pois a aversão ou afeição à carne não estaria associada ao grau de intimidade entre humanos e animais. Trata-se de comê-los de modo despersonalizado, isto é, como carne e sangue transformados em comida, como no caso da sobremesa elaborada com o sangue de porcos. A compreensão dessas atividades sob o viés moral não faria jus às significações atribuídas aos animais no sertão seridoense.

O capítulo de Pereira et al. retrata o projeto de inventário da "lida campeira' no pampa sul-rio-grandense, como parte do Inventário Nacional de Referências Culturais do IPHAN. As autoras abordam o tema da domesticidade em relação às atividades e aos saberes que os campeiros consideram tradicionais, opondo-se assim a doma "gaúcha" àquela dita "racional”. Nesse caso, "a dubiedade da relação com os rebanhos está na dificuldade de diferenciar a atividade de criação da de caça” (:202). Os ofícios e os modos de fazer na pecuária campeira são descritos como parte de um domínio que repercute sobre os modos de vida na região, onde as "noções de tradição e cultura transitam - como pessoas, animais e utensílios - entre o campo e a cidade" (ibid.).

Na terceira parte, Modos de comer, formas de existir, o tema da alimentação é debatido em pesquisas que exploram as suas implicações em diferentes contextos. No trabalho de Mayra Vergotti Ferrigno, o consumo alimentar aparece associado às estratégias políticas do veganismo. Os discursos de seus adeptos afirmam não apenas a possibilidade, mas a necessidade de fazer política por meio da alimentação (:23). O empenho em campanhas de boicote comercial configura uma arena política, a partir da qual são criticados o consumismo e os "hábitos culturais" que dependem do sofrimento imposto aos animais. O veganismo se apoia, assim, na defesa de um "alargamento da fronteira da moralidade" (:214) e da urgência do progresso de uma "cultura ecológica" (:216), onde a responsabilidade pelos problemas ambientais estaria imposta a todos. Os "direitos dos animais", os "direitos da natureza" e o "biocentrismo" surgem como princípios que afirmam a possibilidade de uma ética não antropocêntrica.

O capítulo de Bernardo Lewgoy explora outra perspectiva dos discursos em defesa dos "direitos dos animais" e que consiste na afirmação de que a alimentação destinada aos pets deveria ser 
"natural", isto é, elaborada a partir de carcaças cruas de animais mortos com o propósito de oferecer aos cachorros uma dieta "original". O autor recupera a polêmica do Pet Food Recall, de 2007, quando centenas de cães e gatos morreram nos Estados Unidos da América em decorrência da contaminação de rações industriais. O trabalho de Lewgoy tem o mérito de demonstrar que é preciso repensar o campo das pesquisas de antropologia da alimentação, já que "a escolha do alimento para o consumo humano e não-humano contém uma miríade de questões dietéticas, morais, políticas e econômicas que ultrapassam a antiga barreira entre as espécies" (:239).

Jean Segata narra a sua etnografia em uma clínica veterinária e reflete sobre questóes recorrentes em torno dos pets. O autor analisa a relação entre a humanização dos animais e o preço dos procedimentos e produtos necessários ao processo. Nesse sentido, "não caberia perguntar se os animais são ou não gente, mas quando - também como e para quem” (:25). Como no trabalho de Andréa Osório, na Parte 1, debatem-se aqui as implicações da "incorporação dos pets nas relações familiares e da formação de famílias multiespecificas", e as "disjunções operadas pela proximidade, pela convivência e pela comensalidade" (:26). Em suma, o problema que norteia a descrição etnográfica diz respeito à "contingencia da humanidade dos animais de estimação - afinal, quando eles são gente? Quais os custos para a manutenção desse estatuto?” (:242). Isto porque o dinheiro que permite a humanização dos animais de estimação também pode configurar um limite socioeconômico que os expõem aos riscos de produtos de baixa qualidade e valor nutricional.

Na parte 4, Entre espécies?, os autores exploram as conceituações em torno das espécies e as vantagens de "uma reflexão antropológica sobre relações inter- ou trans específicas" (:27-28). O capítulo de Guilherme José da Silva e Sá analisa, com o auxílio de registros documentais, "eventos ocorridos em zoológicos brasileiros" e que o autor convencionou chamar de "narrativas de eventos trans específicos" (:267). A trans especificidade ocorreria "quando, de alguma forma, não mais reconhecemos nas espécies em foco comportamentos, ações, hábitos, performances, etc., conforme as expectativas que temos delas" (ibid.). Os parques zoológicos nos permitiriam observar em que medida operam uma "descontextualização estratégica", ao trazer à "domesticidade urbana personagens da vida selvagem, funcionando também como máquinas de sujeição, de produção de sujeitos-animais, além de publicizarem a vida privada não humana" (:281). Justamente por isso, os zoológicos poderiam ser vistos como "espaços instáveis de mediação entre natureza e cultura" (ibid.).

O capítulo seguinte, de Flávio Leonel Abreu da Silveira, aborda um espaço similar ao analisado por Guilherme Sá. Trata-se do Jardim Botânico Bosque Rodrigues Alves, situado na área urbana de Belém, no Pará. Silveira descreve as "consequências existenciais que afetam mutuamente as espécies em interação" (:296) nos diferentes espaços do Jardim Botânico: o seu zoológico e a conservação ex situ; e as espécies de vida "semi-livre" e "livre", na conservação in situ, que entram em contato com os visitantes e participam de diferentes formas de socialidade.

Marcos Carvalho apresenta uma etnografia que revela os afetos e os limites do uso da experimentação animal em dois laboratórios no Rio de Janeiro. Enquanto um dos laboratórios abandonou o uso de animais e passou a contar com voluntários humanos, o outro realiza experiências in vivo com roedores. Em ambos os casos, colocam-se os problemas da empatia entre cientistas e cobaias, do sofrimento e do 
mal-estar diante da agência e da recalcitrância dos animais, e da necessidade de sacrificá-los quando se tornam dispensáveis à pesquisa. Diferentemente do que costumamos supor, o autor demonstra que a experimentação animal não é um fenômeno homogêneo e tampouco definitivo, já que os experimentos in vivo podem ser substituídos por modelos experimentais alternativos. Se muitas vezes ouvimos dizer que os "informantes humanos" dificultam as pesquisas de cientistas sociais pois podem mentir, omitir e trapacear os pesquisadores, a imagem objetificada (e de suposta inércia) das cobaias não faz jus aos meios utilizados pelos animais para resistir e dificultar a sua utilização nos experimentos.

Na parte 5, Carisma e inimizade, os capítulos exploram os diferentes vínculos e ambiguidades nas relações humano-animal. Creado et al. descrevem os esforços de conservação de duas "espécies emblemáticas" da "megafauna carismática": as tartarugas marinhas no litoral capixaba e os elefantes na África do Sul. No caso dos elefantes, a questão se torna ainda mais premente que no caso das tartarugas, pois embora sejam considerados animais inteligentes e populares, devido à sua aparição em desenhos e filmes destinados ao público infantil, eles também figuram-se como "inimigos" de populações humanas que coabitam as áreas em que costumam transitar, tornando-se eventuais alvos de ataques dos elefantes. Além disso, ainda no caso sul-africano, a reivindicação de proteção ambiental de áreas privadas refletiria a preocupação de uma elite de origem não africana para garantir a continuidade da posse de grandes extensões de terras. A conservação das "espécies emblemáticas" evoca a noção de "paradigma ecossistêmico", que consiste, por exemplo, na preocupação em torno de alternativas ao abate e ao consumo desses animais por parte de comunidades de pescadores e povos indígenas, como no caso das tartarugas no Brasil (:369).

Ciméa Bevilaqua discute a seguir a trama de processos judiciais envolvendo ataques de cães no Brasil e na Inglaterra. Neste capítulo, a autora apresenta episódios que evidenciam a percepção de uma suposta traição que irromperia no vínculo humano-animal e a conversão da figura dos cães: de amigos fiéis a agressores. Diferentemente do que se poderia imaginar, processos judiciais cujos protagonistas são animais não dizem respeito apenas ao fenômeno da popularização do mercado dos pets no século XX. No caso brasileiro, as consequências dos ataques aparecem em primeiro plano: "quando a lei estabelece a responsabilidade objetiva do dono pelos danos causados pelo animal, a questão jurídica relevante para o desfecho do processo não é a qualificação dos atos de ambos, [...] mas o montante da indenização" (:401). No cálculo dos valores indenizatórios são os atributos das pessoas (e não os dos animais) que interessam ao poder Judiciário. Os processos analisados por Bevilaqua demonstram a existência de "diferentes mundos institucionais, povoados por entes de natureza distinta: neles, um cão que morde uma pessoa de fato não faz a mesma coisa, e sua ação não produz os mesmos efeitos" (:402) em todos os lugares.

Vale lembrar que as relações humano-animal incluem animais que geralmente não são vistos como tais, como é o caso dos mosquitos e outros insetos que compartilham conosco o reino Animalia. O capítulo de Felipe Vander Velden trata de animais que costumamos definir como matáveis, inúteis ou simplesmente perigosos. Para o povo indígena Karitiana, na Amazônia rondoniense, os plasmódios e os mosquitos anofelinos, conhecidos como "pequenos espíritos vampiros", "não são (ou ao menos não são os únicos) vetores ou causas da malária” (:36). A questão diz respeito, principalmente, à conside- 
ração sobre a presença dos mosquitos como seres com os quais é preciso conviver, negociando-se questões de vida e de morte. Vander Velden descreve um contexto que não aponta para um mundo marcado pela insegurança, pelo risco e pelo medo, tal como destacado por alguns sociólogos e também pelos sujeitos presentes em outras etnografias nesta coletânea. O caso karitiana sugere outras "possibilidades de negociação da convivência entre espécies e da relação, sempre tensa e complexa, entre anfitriões e visitantes" (:429).

Ao concluir a leitura de Parentes, vítimas, sujeitos percebe-se que o convite para observar os animais em contextos, conforme anunciado no início do livro, revela o sucesso de um projeto coletivo e orientado pelo investimento etnográfico em torno das relações entre humanos e animais. Os autores da coletânea transformam uma suposta antinomia "em uma miríade de formas flexionadas, modos à mesa e distâncias geográficas ou simbólicas, todas elas efeitos dos encontros sempre imprevisíveis e contextuais entre variadas formas de vida" (:37). Trata-se de uma leitura obrigatória e inspiradora, não apenas para os antropólogos, mas para todos os interessados no estudo das relações humano-animal.

Messias Basques é mestre em Antropologia Social pela Universidade Federal de São Carlos, doutorando no PPGAS/Museu Nacional e professor substituto na Universidade Federal do Espirito Santo (UFES).

RECEBIDO: 29/03/2018

APROVADO: $30 / 09 / 2018$ 